\title{
Proposing a framework for airline service quality evaluation using Type-2 Fuzzy TOPSIS and non-parametric analysis
}

\section{Navid Haghighat}

Shahed University,

Tehran Province, Tehran, Iran

MSc, Department of Industrial Management

\section{open 2 access (co) dol}

\section{Article history:}

Received: August 12, 2017

1st Revision: September 10, 2017

Accepted: October 26, 2017

\section{DOI:}

10.14254/jsdtl.2017.2-2.1

\begin{abstract}
This paper focuses on evaluating airline service quality from the perspective of passengers' view. Until now a lot of researches has been performed in airline service quality evaluation in the world but a little research has been conducted in Iran, yet. In this study, a framework for measuring airline service quality in Iran is proposed. After reviewing airline service quality criteria, SSQAI model was selected because of its comprehensiveness in covering airline service quality dimensions. SSQAI questionnaire items were redesigned to adopt with Iranian airlines requirements and environmental circumstances in the Iran's economic and cultural context. This study includes fuzzy decision-making theory, considering the possible fuzzy subjective judgment of the evaluators during airline service quality evaluation. Fuzzy TOPSIS have been applied for ranking airlines service quality performances. Three major Iranian airlines which have the most passenger transfer volumes in domestic and foreign flights were chosen for evaluation in this research. Results demonstrated Mahan airline has got the best service quality performance rank in gaining passengers' satisfaction with delivery of high-quality services to its passengers, among the three major Iranian airlines. IranAir and Aseman airlines placed in the second and third rank, respectively, according to passenger's evaluation. Statistical analysis has been used in analyzing passenger responses. Due to the abnormality of data, Non-parametric tests were applied. To demonstrate airline ranks in every criterion separately, Friedman test was performed. Variance analysis and Tukey test were applied to study the influence of increasing in age and educational level of passengers on degree of their satisfaction from airline's service quality. Results showed that age has no significant relation to passenger satisfaction of airlines, however, increasing in educational level demonstrated a negative impact on passengers' satisfaction with airline's service quality.
\end{abstract}

Keywords: airline service quality, passenger satisfaction, nonparametric analysis, Type-2 Fuzzy Set, Fuzzy TOPSIS.

Corresponding author: Navid Haghighat

E-mail: navid.haqiqat@gmail.com 


\section{Introduction}

Since increasing in air travel rates, competition between Iranian airlines has grown in recent years. Although a lot of researches has been conducted in airline service quality evaluation in different countries, there is still a little research concerning airline service quality in Iran.

Nowadays, delivering high-quality services has become a marketing requirement for airline companies which want to survive in this competitive environment (Ostrowski, O'Brien, \& Gordon, 1993). In this competitive environment, delivering service quality in a desirable manner, is essential for the airline's competitiveness and sustained growth because of passenger's high expectations and rapid development of transport technology that has made the world into the global village. In order to better serve passenger needs, airlines have to pay attention to passenger's expectations from their services. Airlines need to discover new ways to increase focusing on essential service items and reduce the time and energy spent on less important service items (Liou, Hsu, Yeh \& Lin, 2011). So they can better manage their budget and have the chance of reducing their prices. In this case, they can cope competitive challenges and avoid losing their passenger with maintaining their perceptions of service quality at a moderate level. Trying to deliver high-quality service to airline passengers, results in retaining existing customers and also, enticing other airlines customers and leads to differentiating airline image from competitors. According to sultan and Simpson Jr (2000) customized services, guarantees, and continuous customer feedback are important factors of a successful service quality strategy as a comprehensive measurement of airlines performance.

Chang and Yeh (2002) argue that since service quality is heterogenic, intangible and inseparable, its measurement quality is difficult. In most industries such as airline industry, only customers can investigate the service value and truly evaluate service quality because they are service consumers. In the airline industry, for improving airline service quality performance, airline managers need a framework enabling them to evaluate the quality of services they offer passengers and help them improve quality in required areas. Since the evaluation is produced from the different view of evaluator's linguistic variables, evaluation process must be conducted in an uncertain, fuzzy environment, to gain more accurate data. A fuzzy multi-criteria model is necessary to deal with "qualitative" (unquantifiable or linguistic) or incomplete information (Opricovic \& Tzeng, 2003).

Fuzzy MADM techniques are powerful decision-making tools that help managers to involve all aspects of the problem in the decision process. Solving problems and making decision in Fuzzy environment leads to more precise and accurate results in ranking and selecting alternatives. Statistical analysis of passengers' responses empowers airline managers in better understanding of passengers service quality needs and would help them in making effective improvement plans for increasing airlines service quality performance. In this paper, combining Fuzzy MADM and statistical analysis with improving SSQAI scale and redesigning its questionnaire, helped in proposing a stable framework for evaluating airline service quality in Iran.

\section{Service quality in airline industry}

Quality is one of the primary drivers of business and is used to differentiate organization's service offering. "Quality" lies at the heart of the organization's strategy to gain competitive advantage (Ghobadian, Speller, \& Jones, 1994). Offering high-quality services will increase customer satisfaction, leading to consumer retention and encouraging recommendations (Nadiri \& Hussain, 2005).

Parasuraman, Zeithaml, and Berry (1985) defined the concept of service quality as a comparison between customers' expectations and actual service performance. Parasuraman, Zeithaml, and Berry (1988) argued that, regardless of the type of service, consumers evaluate service quality using similar criteria, which can be grouped into five dimensions. They proposed their five dimensions' model with 22 items measurement scale (called SERVQUAL). The five Dimensions of SERVQUAL are reliability, responsiveness, assurance, empathy and, tangibles which were developed based on Parasuraman et al.'s (1985) study in which they proposed ten dimensions of service quality. Although SERVQUAL has been widely applied to various industries, including airline industry (Nel, Pitt, \& Berthon, 1997; Park, Gilbert, \& Wong, 2003; Robertson, \& Wu, 2004), this scale has been highly criticized in the literature (Bitner, 1990; Bolton \& Drew, 1991; Park, Robertson, \& Wu, 2006). Cronin and Taylor (1994) consider that SERVQUAL has a naturally flawed concept because of its ill-judged adoption of the 
disconfirmation model. Gilbert and Wong (2003) and Liou et al, (2011) state that however SERVQUAL has been widely used to measure service quality in a variety of industries, no two providers of a service are exactly alike. Park et al. (2006) note that the five dimensions with twenty-two items of SERVQUAL scale can't easily be applied to the airline industry because this scale has not mentioned some of the important criteria in airline service quality such as in-flight meals, seating comfort, seat space and leg room.

Cronin and Taylor (1992) developed a performance-based model of service quality called SERVPERF that measures service quality only based on customers' perceptions of the service performance. This model is a variation of SERVQUAL since uses the same criteria of SERVQUAL model. SERVPERF is an applicable and useful tool for measuring service quality. However, Cunningham, Young, and Lee (2004) mentioned that since SERVPERF uses the same dimensions and items of SERVQUAL, it has failed to measure industry-specific dimensions of service quality in the airline industry. As Ghobadian et al. (1994) stated, service quality is a multi-dimensional phenomenon and utility value of its determinants are situation-dependent.

Chang and Yeh (2002) assert that attributes of service quality are context dependent and should be selected based on the service environment investigated. Due to this fact, many researchers have adopted different criteria for evaluating airline service, e.g. Elliott and Roach (1993) evaluated timelines, comfort of the seat, luggage transportation, quality of food and beverage, check-in process and inboard service factors in measuring airline service quality. Ostrowski et al. (1993) defined customer-loyalty, timeliness, Food and beverage quality, and comfort of the seat as the service quality and factors. Liou et al. (2011) found twenty-eight criteria classified under dimensions of Booking service, Ticketing service, Check-in, Baggage handling, boarding process, Cabin service, Baggage claim, Responsiveness to realize passengers' satisfaction of airlines service quality. Truitt and Haynes (1994) offered seven criteria for evaluating airline service quality that are customer complaints handling, check-in process, the convenience of transit, process of luggage, timeliness, clearness of seat, and Food and beverage quality. Laming and Mason (2014) expressed that US Department of Transportation Rates airlines quality with on-time performance, customer complaints denied boarding, mishandled baggage.

Recently, evaluating service quality base on the hierarchical concept is taken into consideration by researchers. Brady and Cronin (2001) suppose that customers form their service quality perceptions on the basis of an evaluation of performance at multiple levels and ultimately combine these evaluations to arrive at an overall service quality perception. Dabholkar, Thorpe \& Rentz's (1996), Brady and Cronin (2001) and Wu, Lin and Hsu (2011) Suggest that service quality should be based on a hierarchical concept. In hierarchical concept, Customers make their judgments of service quality based on a series of factors that are specific to the evaluated service. Base on this approach, customers form their evaluation of primary dimensions on assessment of the corresponding subdimensions. Wu and Cheng (2013) introduced SSQAI model with eleven criteria in four dimensions specialized for evaluating airline service quality. The SSQAI model is a performance-based measurement scale on the basis of hierarchical structures in measuring service quality. SSQAI (see Fig. 1) is developed based on Dabholkar et al. (1996), Brady and Cronin's (2001) and Caro and Garcia's (2007) models.

Park et al. (2006) indicate that many airlines can't find a proper scale to evaluate service quality to assess and improve their service performance. However, many studies have used conventional statistical techniques to test hypotheses and generate airline service quality criteria such as Pakdil and Aydin (2007) and Gursoy, Chen and Kim (2005). In recent years the researchers have tended to apply Fuzzy Multiple Criteria Decision-Making (FMCDM) techniques to strength the comprehensiveness and reasonableness of the decision-making process (Tsaur et al., 2002). The researchers have implemented MCDM methods to measure airlines integrated service quality level and to find weak areas and make suggestions for improvement (Chang \& Yeh, 2002; Liou \& Tzeng, 2007; Tsaur et al., 2002; Liou et al., 2011). Tsaur, Chang, and Yeh (2002) used SERVQUAL dimensions to derivate service quality attributes and performed AHP and TOPSIS in ranking the airlines. They stated that courtesy, safety, and comfort are the most important attributes.

Chang and Yeh (2002) performed fuzzy multi-criteria analysis for ranking four Taiwan's domestic airlines based on the concepts of the degree of optimality and the ideal solution. Fifteen service quality attributes classified in eight dimensions were ranked according to passengers' 
responses. Liou and Tzeng (2007) applied Fuzzy integral, AHP and Grey Relation Analysis to rank service quality performance of six international airlines. In this paper, the SSQAI model is improved and a framework applicable to measure airline service quality in Iran is designed.

\section{Methodology}

After reviewing airline service quality criteria, SSQAI scale was adopted in this study, since it represents a valid and reliable tool for assessing service quality in the airline industry (see Fig. 1). the criteria on the SSQAI model and their symbols used in this study are shown in Table. 1. After collecting customer opinions, and using criteria weights determined by experts, ranking of these airlines was calculated using trapezoidal fuzzy TOPSIS. Fuzzy TOPSIS calculation was constructed in excel 2016.

\section{Table 1: Airline measurement dimensions and criteria}

Dimensions/Criteria

Index

\begin{tabular}{lc}
\hline Interaction Quality & \\
\hline Conduct & $\mathrm{C}_{1}$ \\
Expertise & $\mathrm{C}_{2}$ \\
Problem-Solving & $\mathrm{C}_{3}$ \\
\hline
\end{tabular}

Physical Environment Quality

\begin{tabular}{lc}
\hline Cleanliness & $\mathrm{C}_{4}$ \\
Comfort & $\mathrm{C}_{5}$ \\
Tangibles & $\mathrm{C}_{6}$ \\
Safety\&Security & $\mathrm{C}_{7}$ \\
\hline Outcome Quality & \\
\hline Valence & $\mathrm{C}_{8}$ \\
Waiting Time & $\mathrm{C}_{9}$ \\
\hline Access Quality & \\
\hline Information & $\mathrm{C}_{10}$ \\
Convenience & $\mathrm{C}_{11}$ \\
\hline
\end{tabular}

Figure 1: Service Quality Dimensions

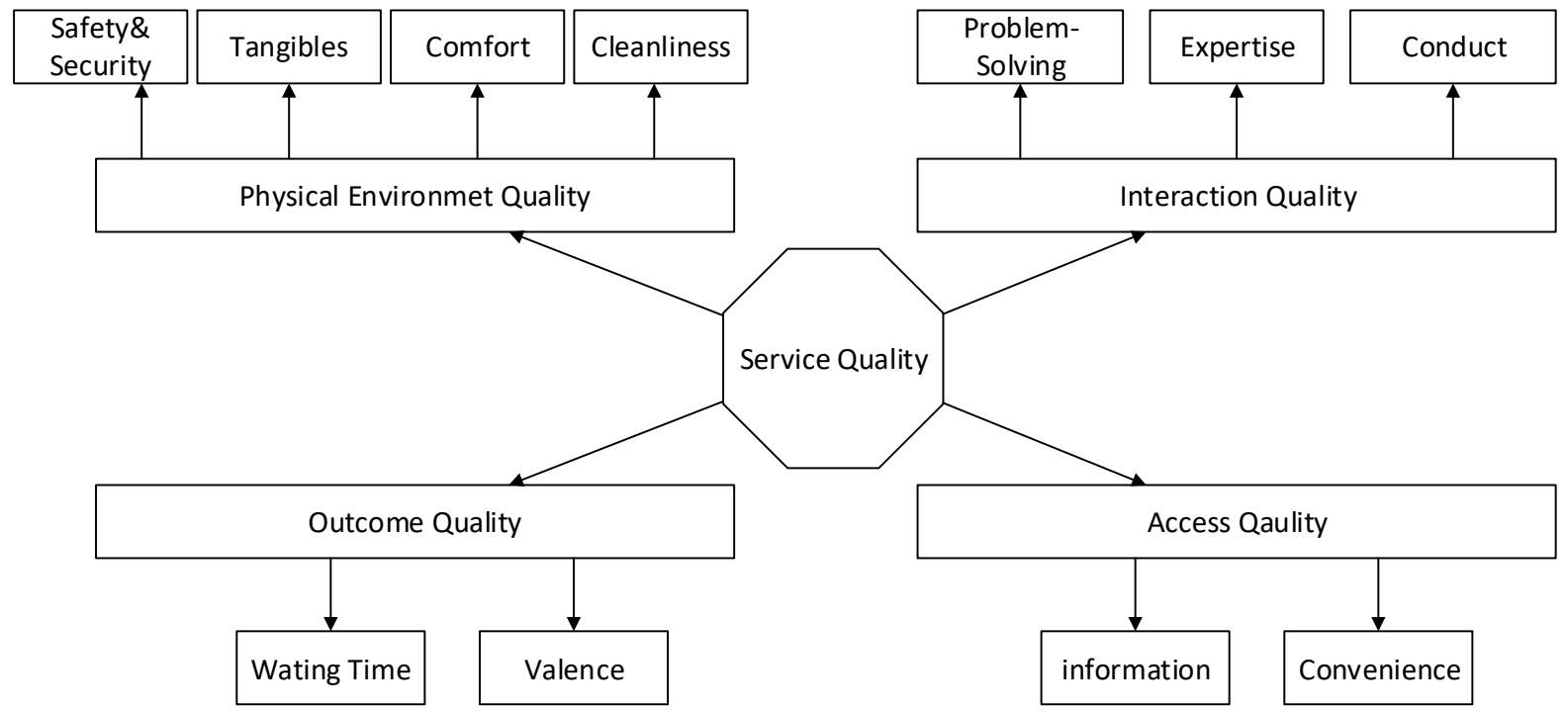

Using statistical analysis for analyzing customer reviews, firstly, normalization test was taken to determine using parametric or non-parametric tests. Shapiro-Wilk and Kolmogorov- Smirnov (K-S) normality tests showed collected data are not normal, so non-parametric tests were applied for 
analyzing passengers' responses. Friedman test was performed to demonstrate airline ranks in every criterion separately. Airlines ranked in all criteria due to customer opinions. Variance analysis and post-hoc Tukey test were applied to study the influence of increasing of age and educational level on degree of passengers' satisfaction with airlines service quality performance.

Three airlines chosen for this research and their symbols are Mahan $\left(A_{1}\right)$, $\operatorname{IranAir}\left(A_{2}\right)$ and Aseman $\left(\mathrm{A}_{3}\right)$ airlines. These airlines were nominated since they are the three oldest Iranian airlines with a powerful background. Moreover, most flight rates and passenger transportation volume among all airlines in Iran belongs to these airlines.

\subsection{Data Collection}

\subsubsection{Experts}

Our experts' Community involved 45 respondents from Tehran and Mashhad. Our experts consist of 12 airline manager, 16 Aviation specialist, 17 Frequent fliers of chosen airline's passengers. Tehran is the capital of Iran and most central airline offices are in Tehran, except Iran Air that its central office is located in Mashhad. So, our experts are from both cities. Questionnaire of this research was designed according to experts' opinions.

\subsubsection{Passengers}

A sample size of 385 respondents was considered in this study to reduce the influence of the statistical assumptions associated with ANOVA. The questionnaire was distributed to passengers in thirteen airline agencies of Mashhad in about four weeks. Mashhad consists of twenty-six regions. Two agencies were selected from each region and the questionnaires were distributed to passengers of this agencies. The questionnaires were distributed doubled because half of the questionnaires were not properly filled and subsequently were dropped. Only candidates who had flown with all of these three chosen airlines in the last recent year at least one time, were selected for participating in answering questionnaires, so data collection was really time-consuming.

\subsection{Questionnaire design}

First, all criteria in evaluating airline service quality were gathered. By consulting Iranian airline experts, it was founded that four dimensions and eleventh sub-criteria of SSQAI model are prober for utilizing in Iran. We tried to redesign and specialize SSQAI instrument questionnaire items to fit with Iran's economic and cultural circumstances and Iranian airlines situations, as well. With the help of airline industry experts, SSQAI items were utilized in a way to be simple and clear, not encountered with the problems such as vacuity of questions of prior models like SERVQUAL. It's believed some of the criteria extracted from literature could be involved in the subset of SSQAI criteria items. So, these criteria were added to our framework questionnaire. Also, some items were changed or dropped due to ensure universality of this model and specializing and localizing this model for using in Iran's airline industry, by taking average scores of experts' opinions in the screening questionnaire.

Each expert had to give scores from 0 to 5 to every item. The average test was applied to scalp questionnaire items and improve stability of the instrument. Items with scores more than 3 were selected to be on final instrument to help with increasing endurance. The final version of our instrument has a total of 64 items representing eleventh criteria of SSQAI airline service quality model (See Table. 2). In this paper, the questionnaire was distributed to gather passengers' ratings of three chosen airlines, Mahan, Iran Air and Aseman. Using fuzzy TOPSIS the three Iranian major airlines were ranked based on the passenger satisfaction with these airlines service quality performance. 


\section{Table 2: Evaluation criteria and Questionnaire items}

Criteria

1. Cabin crew are kind and polite to me.

Items

2. The employee of (reservation, sales, ticket issuing, identification, and handling) behave respectfully and politely with me.

3. The airline employees' attitude demonstrates their willingness to help me.

4. I can depend on the airline employees being friendly.

5. The employees' attitude shows me that they understand my needs.

Conduct 6. The employees' behavior allows me to trust their services.

7. The pilot's speech during flight is clear and soothing.

8. The employees carefully pay attention to passengers depending on the type of traveler (women, men, children, adolescents, persons with disabilities, first class or ...).

9. The employees understand my specific needs.

10. The employees pay attention to every single traveler.

11. The employees always provide me with their best services.

12. The employees try their best to provide services to me.

13. The airline employees understand that I relay on their professional knowledge to satisfy my needs.

14. I can count on the airline employees knowing their jobs/responsibilities.

Expertise $\quad 15$. The airline employees are competent.

16. Cabin crew speak fluently and coherently.

17. The airline employees of baggage delivery are quick and accurate.

18. The Airline procedure of check passenger identification and Ticketing and boarding pass issuance is quick and accurate.

19. When I have a problem, the airline employees show a sincere interest in solving it.

Problem- 20. The employees consume enough time to solve my problem.

solving 21. The employees understand the importance of resolving my complaints.

22. The employees are able to handle my complaints directly and immediately.

23. The cabin is tidy and clean.

Cleanliness 24. The toilet in the cabin is clean.

25. The employees have clean and neat appearance.

26. I feel comfortable in Flying with this airline.

27 . The seat in the cabin is comfortable.

Comfort 28. I feel comfortable with the actual temperature in the cabin.

29. There is a variety of newspapers and magazines in flight.

30. Flights entertainment services of this airline are favorable.

31 . The on-site queening at the airport is understanding and predictable.

32. I feel comfortable with the volume of noise in the cabin.

33. The airlines facility is well designed.

Tangibles 34. The layout of airlines serves my need.

35. Ticket and travel services offices and counters are pretty and equipped.

36. The Quality of meals and drinks on the plane is favorable.

37. The Way meals are served on the plane, is perfect.

Safety \& 38. The cabin crew describe how to use safety equipment, such as (oxygen masks, vests, boat,

Security etc.) very well and precisely.

39. There are noticeable sprinkler systems in the cabin.

40. I believe that the airline tries to give me what I want.

Valence $\quad 41$. I would say that I feel good about what I receive from airlines.

42. I would evaluate the outcome of airlines services favorably.

43. I will recommend Traveling with this airline flights to my friends and acquaintances.

44. The airline tries to minimize my waiting time.

45. The airline understands that waiting time is important for me.

46. Airline employees provide services quickly and in the shortest
47. I rarely have to wait long to receive the airline services i need.

48. There is a rare delay before or during aircraft flight and the flight schedules are accurately according to the announced program.

49. The airline keep me well-informed about services i need.

$\begin{array}{ll}\text { Information } & \text { 50. The airline tells me the accurate time on which it provides servic } \\ 51 . \text { The airline understands the information the passengers need. }\end{array}$

52. Airlines website has interactive features (for example, online answering to questions). 
53. Airlines offers adequate and proper flight information to passengers.

54. I can Easily access to my required information accurately and up to date in 24 hours a day.

55. Website Instructions explaining how to get airline services are legible and understandable.

56. The Airline website provides suitable information of various services the company offers.

57. Airline offers services (before or during the flight) based on schedule formerly announced.

58. The Airline web services are desirable and efficient.

59. The reservation and ticketing systems are convenient.

60. The airline provides me with enough flights and convenient flight schedules

Convenience

61. Passenger transportation services from the output gate to the aircraft is efficient and desirable.

62. Compensation procedure in case of flight delays or cancelation or air accidents, is proper and convenience.

63. The passenger load displacement process is convenient and efficient.

64. Electronic payment services through airline website are easy and convenient.

Descriptive statistics of the respondents is shown in Table. 3.

\section{Table 3: Descriptive statistics of the respondents}

\begin{tabular}{lcc}
\multicolumn{1}{c}{ Attributes/Options } & Frequency & Percentage \\
\hline Gender & & 74.8 \\
Male & 288 & 25.2 \\
Female & 97 & 14.6 \\
Marital status & & 85.4 \\
Single & 56 & 14 \\
Married & 329 & 32 \\
Age & & 26.5 \\
18-29 & 54 & 14 \\
$30-41$ & 123 & 10.1 \\
$42-53$ & 102 & 3.4 \\
$54-65$ & 54 & 9.4 \\
$66-77$ & 39 & 34.8 \\
$78-89$ & 13 & 12.7 \\
Education & & 31.7 \\
Below Diploma & 36 & 7.5 \\
High school Diploma & 134 & 3.9 \\
Associate & 49 & \\
Bachelor & 122 & \\
Master & 29 & 15 \\
PhD & 15 & \\
\hline
\end{tabular}

\section{Fuzzy Set and Type-2 Fuzzy Number}

Fuzzy set theory aids in measuring the ambiguity of concepts that are associated with human being's subjective judgment. Lingual expressions, for example, satisfied, fair, dissatisfied, are regarded as the natural representation of the preference or judgment. The fuzzy linguistic variable reflects different aspects of human language. Its value represents the range from natural to artificial language. When the values or meanings of a linguistic factor are being reflected, the resulting variable must also reflect appropriate modes of change for that linguistic factor (Chen \& Chen, 2010).

Zadeh (1975) proposed using values ranging from 0 to 1 for showing the membership of the objects in a fuzzy set. The membership degree of the fuzzy set can be described with triangular, trapezoidal, Gaussian, sigmoidal functions or can be formed with different functions. Trapezoidal fuzzy numbers are useful in promoting representation and information processing in a fuzzy environment and their computational simplicity. Trapezoidal fuzzy numbers can be expressed as $\left(\mathrm{n}_{1}, \mathrm{n}_{2}, \mathrm{n}_{3}, \mathrm{n}_{4}\right)$. A trapezoidal fuzzy number is shown in Fig. 2. 
Figure 2: A trapezoidal fuzzy number

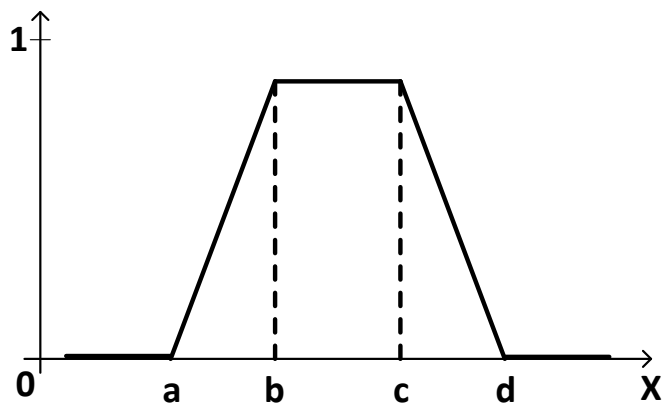

\section{Fuzzy TOPSIS}

The technique for order preference by similarity to an ideal solution (TOPSIS) was developed by Hwang and Yoon (1981). Based on the concept, any chosen alternative should have the shortest distance from the ideal solution and the farthest distance from the negative-ideal solution (Opricovic \& Tzeng, 2003). Trapezoidal fuzzy numbers are useful in promoting representation and information processing in a fuzzy environment and their computational simplicity. In this study, trapezoidal fuzzy numbers are adopted in the fuzzy TOPSIS calculation. A developed method of Fuzzy TOPSIS offered by Chen (2000) is used in this paper. Fuzzy TOPSIS analysis is conducted as follows:

\subsection{Define linguistic scale}

Linguistic variables used in Fuzzy TOPSIS are shown in Table. 4. This scale had been formerly applied in fuzzy TOPSIS analysis by Ertuğrul and Güneș (2007).

\begin{tabular}{lc}
\hline Table 4: Fuzzy Linguistic Variables & Trapezoidal Fuzzy Numbers \\
\hline Linguistic Variables & $(0,0,1,2)$ \\
\hline Very Poor(VP) & $(1,2,2,3)$ \\
Poor(P) & $(2,3,4,5)$ \\
Medium Poor(MP) & $(4,5,5,6)$ \\
Fair(F) & $(5,6,7,8)$ \\
Medium Good(MG) & $(7,8,8,9)$ \\
Good(G) & $(8,9,10,10)$ \\
Very Good(VG) & \\
\hline
\end{tabular}

\subsection{Establish the initial decision matrix}

If $A_{i}=A_{1} ; A_{2} ; \ldots ; A_{m}$ are possible alternatives among which decision makers have to choose, $C_{j}=C_{1}$; $\mathrm{C}_{2} ; \ldots ; \mathrm{C}_{\mathrm{n}}$ are criteria with which alternative performance are measured. $\mathrm{X}_{\mathrm{ij}}$ is the rating of alternative $\mathrm{A}_{\mathrm{i}}$. If we have $\mathrm{K}$ passengers participating to compare alternatives (in this paper, the three airlines), the aggregated fuzzy ratings of $\mathrm{K}$ passengers can be calculated as:

$$
\begin{gathered}
X_{i j k}=\left(a_{i j k}, b_{i j k}, c_{i j k}, d_{i j k}\right) \\
a_{i j}=\min \left\{a_{i j k}\right\} \\
b_{i j}=\frac{1}{k} \sum_{k=1}^{k} b_{i j k} \\
c_{i j}=\frac{1}{k} \sum_{k=1}^{k} c_{i j k} \\
d_{i j}=\max \left\{d_{i j k}\right\}
\end{gathered}
$$


$\mathrm{W}_{\mathrm{j}}$ is the weight of criterion $\mathrm{C}_{\mathrm{j}}$.The aggregated weights can be obtained directly from expert opinions, with the same technique as aggregated fuzzy ratings of passengers, here $P$ defines the number of experts.

$$
\begin{aligned}
& W=\left[w_{1}, w_{2}, \ldots, w_{n}\right] \\
& w_{j 1}=\operatorname{Min}\left\{w_{j k 1}\right\} \\
& w_{j 2}=\frac{\sum_{p=1}^{p} w_{j k 2}}{p} \\
& w_{j 3}=\frac{\sum_{p=1}^{p} w_{j k 3}}{p} \\
& w_{j 4}=\operatorname{Max}\left\{w_{j k 4}\right\}
\end{aligned}
$$

In this paper, the aggregated weights are generated based on experts' responses. The initial fuzzy decision matrix is constructed in Table 5.

\section{Table 5: Fuzzy design matrix}

\begin{tabular}{ccccc} 
Criteria & $\mathbf{A}_{\mathbf{1}}$ & $\mathbf{A}_{\mathbf{2}}$ & $\mathbf{A}_{\mathbf{3}}$ & Weight \\
\hline $\mathbf{C}_{\mathbf{1}}$ & $(5.17,7.26,7.85,9.33)$ & $(3.83,6.23,6.73,8.67)$ & $(3.42,5.55,6.02,8.17)$ & 0.010458 \\
$\mathbf{C}_{\mathbf{2}}$ & $(4.5,7.71,8.35,10)$ & $(4.33,7.04,7.6,9.67)$ & $(2.67,5.61,6.14,8.33)$ & 0.040405 \\
$\mathbf{C}_{\mathbf{3}}$ & $(4.25,7.23,7.8,9.75)$ & $(1.75,4.98,5.45,8.5)$ & $(0.25,2.54,3.07,6.5)$ & 0.099067 \\
$\mathbf{C}_{\mathbf{4}}$ & $(4.33,7.87,8.54,10)$ & $(4.33,7.56,8.18,10)$ & $(3.33,7.02,7.55,10)$ & 0.008452 \\
$\mathbf{C}_{\mathbf{5}}$ & $(3.8,6.73,7.28,9.6)$ & $(2.6,5.36,5.89,8.4)$ & $(1.4,3.94,4.48,7.2)$ & 0.062 \\
$\mathbf{C}_{\mathbf{6}}$ & $(3.86,6.41,6.95,9.14)$ & $(2.86,5.35,5.87,8.14)$ & $(1.43,3.73,4.24,7)$ & 0.088996 \\
$\mathbf{C}_{\mathbf{7}}$ & $(2,5.79,6.39,9.5)$ & $(2.5,5.58,6.16,9)$ & $(1,4.18,4.71,8.5)$ & 0.102017 \\
$\mathbf{C}_{\mathbf{8}}$ & $(4,7.5,8.1,10)$ & $(3.5,6.65,7.17,9.5)$ & $(2.5,5.4,5.89,8.75)$ & 0.475208 \\
$\mathbf{C}_{\mathbf{9}}$ & $(4.4,7.22,7.8,9.8)$ & $(3.4,6.21,6.73,9.4)$ & $(1.13,3.4,3.92,6.63)$ & 0.017127 \\
$\mathbf{C}_{\mathbf{1 0}}$ & $(4,6.65,7.2,9.63)$ & $(2.63,4.88,5.38,8.25)$ & $(1.13,3.4,3.92,6.63)$ & 0.027136 \\
$\mathbf{C}_{\mathbf{1 1}}$ & $(4,6.46,7,9.13)$ & $(2.88,5.49,6,8.38)$ & $(2,4.47,5,7.5)$ & 0.069135 \\
\hline
\end{tabular}

\subsection{Calculate the normalized decision matrix}

To avoid the complicated normalization formula used in classical TOPSIS, the linear scale transformation can be used to transform the various criteria scales into a comparable scale. The normalized value $r_{i j}$ is calculated as:

$$
\begin{gathered}
d_{j}^{*}=\max d_{i j} \\
a_{j}^{-}=\min a_{i j}
\end{gathered}
$$

Now, $\tilde{r}_{i j}^{*}$ and $\tilde{r}_{i j}^{-}$, can be calculated,

$$
\begin{aligned}
& \tilde{r}_{i j}^{*}=\left(\frac{a}{d_{j}^{*}}, \frac{b}{d_{j}^{*}}, \frac{c}{d_{j}^{*}}, \frac{d}{d_{j}^{*}}\right) \\
& \tilde{r}_{i j}^{-}=\left(\frac{a_{j}^{-}}{d_{i j}}, \frac{a_{j}^{-}}{d_{i j}}, \frac{a_{j}^{-}}{d_{i j}}, \frac{a_{j}^{-}}{d_{i j}}\right)
\end{aligned}
$$

Matrix $\tilde{R}$ is constructed as follows:

$$
\tilde{R}=\left[r_{i j}\right]_{m \times n} i=1,2, . ., m ; j=1,2, \ldots, n
$$


The normalized fuzzy decision matrix is shown in Table. 6.

\section{Table 6: Normalized fuzzy decision matrix}

\begin{tabular}{cccc} 
Criteria & $\mathbf{A}_{\mathbf{1}}$ & $\mathbf{A}_{\mathbf{2}}$ & $\mathbf{A}_{\mathbf{3}}$ \\
\hline $\mathbf{C}_{\mathbf{1}}$ & $(0.55,0.78,0.84,1)$ & $(0.41,0.67,0.72,0.93)$ & $(0.37,0.59,0.65,0.88)$ \\
$\mathbf{C}_{\mathbf{2}}$ & $(0.45,0.77,0.84,1)$ & $(0.43,0.7,0.76,0.97)$ & $(0.27,0.56,0.61,0.83)$ \\
$\mathbf{C}_{\mathbf{3}}$ & $(0.44,0.74,0.8,1)$ & $(0.18,0.51,0.56,0.87)$ & $(0.03,0.26,0.31,0.67)$ \\
$\mathbf{C}_{\mathbf{4}}$ & $(0.43,0.79,0.85,1)$ & $(0.43,0.76,0.82,1)$ & $(0.33,0.7,0.76,1)$ \\
$\mathbf{C}_{\mathbf{5}}$ & $(0.4,0.7,0.76,1)$ & $(0.27,0.56,0.61,0.88)$ & $(0.15,0.41,0.47,0.75)$ \\
$\mathbf{C}_{\mathbf{6}}$ & $(0.42,0.7,0.76,1)$ & $(0.31,0.59,0.64,0.89)$ & $(0.16,0.41,0.46,0.77)$ \\
$\mathbf{C}_{\mathbf{7}}$ & $(0.21,0.61,0.67,1)$ & $(0.26,0.59,0.65,0.95)$ & $(0.11,0.44,0.5,0.89)$ \\
$\mathbf{C}_{\mathbf{8}}$ & $(0.4,0.75,0.81,1)$ & $(0.35,0.66,0.72,0.95)$ & $(0.25,0.54,0.59,0.88)$ \\
$\mathbf{C}_{\mathbf{9}}$ & $(0.45,0.74,0.8,1)$ & $(0.35,0.63,0.69,0.96)$ & $(0.11,0.35,0.4,0.68)$ \\
$\mathbf{C}_{\mathbf{1 0}}$ & $(0.42,0.69,0.75,1)$ & $(0.27,0.51,0.56,0.86)$ & $(0.12,0.35,0.41,0.69)$ \\
$\mathbf{C}_{\mathbf{1 1}}$ & $(0.44,0.71,0.77,1)$ & $(0.32,0.6,0.66,0.92)$ & $(0.22,0.49,0.55,0.82)$ \\
\hline
\end{tabular}

\subsection{Calculate the weighted normalized decision matrix}

Weights of criteria produced formerly in Fuzzy ANP with experts opinions, are used here. The weighted normalized value is $\mathrm{V}_{\mathrm{ij}}$ and is calculated as:

$$
\begin{aligned}
& v_{i j}=r_{i j} \times w_{j} \\
& V=\left[v_{i j}\right]_{m \times n} i=1,2, . ., m ; j=1,2, \ldots, n \\
& V=\left[\begin{array}{lll}
v_{11} & v_{1 j} & v_{1 n} \\
v_{i 1} & v_{i j} & v_{i n} \\
v_{m 1} & v_{m j} & v_{m n}
\end{array}\right] \\
& v_{i j}=r_{i j} \times w_{j}=\left(\frac{a_{i j}}{d_{j}^{*}}, \frac{b_{i j}}{d_{j}^{*}}, \frac{c_{i j}}{d_{j}^{*}}, \frac{d_{i j}}{d_{j}^{*}}\right) \cdot\left(w_{j 1}, w_{j 2}, w_{j 3}, w_{j 4}\right)=\left(\frac{a}{d_{j}^{*}} w_{j 1}, \frac{b}{d_{j}^{*}} w_{j 2}, \frac{c}{d_{j}^{*}} \cdot w_{j 3}, \frac{d}{d_{j}^{*}}, w_{j 4}\right) \\
& v_{i j}=r_{i j} \times w_{j}=\left(\frac{a_{j}^{-}}{d_{i j}}, \frac{a_{j}^{-}}{c_{i j}}, \frac{a_{j}^{-}}{b_{i j}}, \frac{a_{j}^{-}}{a_{i j}}\right) \cdot\left(w_{j 1}, w_{j 2}, w_{j 3}, w_{j 4}\right)=\left(\frac{a_{j}^{-}}{d_{i j}} w_{j 1}, \frac{a_{j}^{-}}{c_{i j}}, w_{j 2}, \frac{a_{j}^{-}}{b_{i j}} w_{j 3}, \frac{d}{a_{i j}} w_{j 4}\right)
\end{aligned}
$$

The weighted normalized fuzzy decision matrix is shown in Table 7.

\section{Table 7: Weighted normalized fuzzy decision matrix}

\begin{tabular}{cccc} 
Criteria & $\mathbf{A}_{\mathbf{1}}$ & $\mathbf{A}_{\mathbf{2}}$ & $\mathbf{A}_{\mathbf{3}}$ \\
\hline $\mathbf{C}_{\mathbf{1}}$ & $(52.93,74.43,80.4,95.62)$ & $(39.27,63.79,68.96,88.79)$ & $(35,56.84,61.69,83.67)$ \\
$\mathbf{C}_{\mathbf{2}}$ & $(11.14,19.08,20.67,24.75)$ & $(10.72,17.43,18.81,23.92)$ & $(6.6,13.89,15.19,20.62)$ \\
$\mathbf{C}_{\mathbf{3}}$ & $(4.4,7.48,8.08,10.09)$ & $(1.81,5.16,5.64,8.8)$ & $(0.26,2.63,3.18,6.73)$ \\
$\mathbf{C}_{\mathbf{4}}$ & $(51.27,93.14,101.02,118.32)$ & $(51.27,89.5,96.76,118.32)$ & $(39.44,83.03,89.38,118.32)$ \\
$\mathbf{C}_{\mathbf{5}}$ & $(6.38,11.3,12.24,16.13)$ & $(4.37,9.01,9.9,14.11)$ & $(2.35,6.62,7.53,12.1)$ \\
$\mathbf{C}_{\mathbf{6}}$ & $(4.74,7.88,8.54,11.24)$ & $(3.51,6.58,7.22,10.01)$ & $(1.76,4.58,5.21,8.6)$ \\
$\mathbf{C}_{\mathbf{7}}$ & $(2.06,5.97,6.6,9.8)$ & $(2.58,5.76,6.35,9.29)$ & $(1.03,4.31,4.85,8.77)$ \\
$\mathbf{C}_{\mathbf{8}}$ & $(0.84,1.58,1.7,2.1)$ & $(0.74,1.4,1.51,2)$ & $(0.53,1.14,1.24,1.84)$ \\
$\mathbf{C}_{\mathbf{9}}$ & $(26.21,43.02,46.48,58.39)$ & $(20.26,36.97,40.1,56)$ & $(6.7,20.24,23.35,39.47)$ \\
$\mathbf{C}_{\mathbf{1 0}}$ & $(15.31,25.45,27.55,36.85)$ & $(10.05,18.68,20.59,31.59)$ & $(4.31,13.01,15,25.37)$ \\
$\mathbf{C}_{\mathbf{1 1}}$ & $(6.34,10.23,11.1,14.46)$ & $(4.56,8.7,9.52,13.28)$ & $(3.17,7.09,7.93,11.89)$ \\
\hline
\end{tabular}




\subsection{Determine the ideal (FPIS, $A^{*}$ ) and negative-ideal (FNIS, $A^{*}$ ) solutions} have:

Chen (2000) has got $V_{j^{+}}=\{1,1,1\}$ and $V_{j^{-}}=\{0,0,0\}$ for simplicity but here for more precise result we

$$
v_{j}^{-}=\operatorname{Min}\left\{v_{i j 1}\right\}, v_{j}^{*}=\operatorname{Max}\left\{v_{i j}\right\}
$$

$v_{j}^{*}$ is the best value of criteria ' $\mathrm{j}$ ' respect to alternative ' $\mathrm{i}$ ', and ${ }^{v_{j}}$ is the worst value of criteria $\mathrm{j}$ respect to alternatives $i$.

$$
A^{-}=\left\{v_{1}^{-}, v_{2}^{-}, \ldots, v_{n}^{-}\right\}, A^{*}=\left\{\begin{array}{c}
\left.v_{1}^{*}, v_{2}^{*}, \ldots, v_{n}^{*}\right\} \\
n_{1}^{*}
\end{array}\right.
$$
Table 8.

$\mathrm{A}^{*}$ shows the positive ideal solution and $\mathrm{A}^{-}$shows the negative ideal solution as demonstrated in Table 8: The ideal and negative-ideal solutions

\begin{tabular}{cccccccccccc} 
& $\mathbf{C}_{\mathbf{1}}$ & $\mathbf{C}_{\mathbf{2}}$ & $\mathbf{C}_{\mathbf{3}}$ & $\mathbf{C}_{\mathbf{4}}$ & $\mathbf{C}_{\mathbf{5}}$ & $\mathbf{C}_{\mathbf{6}}$ & $\mathbf{C}_{\mathbf{7}}$ & $\mathbf{C}_{\mathbf{8}}$ & $\mathbf{C}_{\mathbf{9}}$ & $\mathbf{C}_{\mathbf{1 0}}$ & $\mathbf{C}_{\mathbf{1 1}}$ \\
\hline $\mathbf{A}^{*}$ & 95.621 & 24.749 & 10.094 & 118.315 & 16.129 & 11.236 & 9.802 & 2.104 & 58.387 & 36.851 & 14.464 \\
$\mathbf{A}-$ & 35.004 & 6.600 & 0.259 & 39.438 & 2.352 & 1.756 & 1.032 & 0.526 & 6.703 & 4.307 & 3.170 \\
\hline
\end{tabular}

\subsection{Calculate the separation measures}

Different from Chen's (2000) approach, Ertugrul, and Gunes (2007) suggest using Euclidean distance for calculating the distance between two fuzzy numbers. The distance between two trapezoidal fuzzy numbers $\left(a_{1}, b_{1}, c_{1}, d_{1}\right)$ and $\left(a_{2}, b_{2}, c_{2}, d_{2}\right)$ can be calculated by using Euclidean distance as:

$$
d_{v}\left(M_{1}, M_{2}\right)=\sqrt{\frac{1}{6}\left[\left(a_{1}-a_{2}\right)^{2}+2\left(b_{1}-b_{2}\right)^{2}+2\left(c_{1}-c_{2}\right)^{2}+\left(d_{1}-d_{2}\right)^{2}\right]}
$$

It is noteworthy that $d\left(v_{i j}, v_{j}^{-}\right)$and $d\left(v_{i j}, v_{j}^{*}\right)$ are crisp numbers.

The distance of each alternative from the fuzzy positive ideal solution (FPIS) and fuzzy negative ideal solution (FNIS) is calculated as:

$$
D_{i j}^{-}=d\left(v_{i j}, v_{j}^{-}\right), D_{i j}^{+}=d\left(v_{i j}, v_{j}^{*}\right)
$$

Distance of each alternative from FPIS and FNIS is shown in Table 9.

\section{Table 9: Distance of each alternative from FPIS and FNIS}

\begin{tabular}{ccccccc}
\hline \multirow{2}{*}{ Criteria } & \multicolumn{3}{c}{$\mathbf{A}_{\mathbf{1}}$} & \multicolumn{2}{c}{$\mathbf{A}_{\mathbf{2}}$} & \multicolumn{2}{c}{$\mathbf{A}_{\mathbf{3}}$} \\
\cline { 2 - 7 } & $\mathbf{D}^{+}$ & $\mathbf{D}^{-}$ & $\mathbf{D}^{+}$ & $\mathbf{D}^{-}$ & $\mathbf{D}^{+}$ & $\mathbf{D}^{-}$ \\
\hline $\mathrm{C}_{1}$ & 56.426 & 90.353 & 81.432 & 66.808 & 94.914 & 52.656 \\
$\mathrm{C}_{2}$ & 2.804 & 5.419 & 3.228 & 4.859 & 4.610 & 3.538 \\
$\mathrm{C}_{3}$ & 1.227 & 3.076 & 2.100 & 2.244 & 2.959 & 1.396 \\
$\mathrm{C}_{4}$ & 13.293 & 23.401 & 14.029 & 22.327 & 16.986 & 20.418 \\
$\mathrm{C}_{5}$ & 2.185 & 3.950 & 2.988 & 3.095 & 3.855 & 2.267 \\
$\mathrm{C}_{6}$ & 1.483 & 2.718 & 1.950 & 2.220 & 2.677 & 1.552 \\
$\mathrm{C}_{7}$ & 1.746 & 2.290 & 1.740 & 2.185 & 2.281 & 1.753 \\
$\mathrm{C}_{8}$ & 0.262 & 0.459 & 0.316 & 0.397 & 0.406 & 0.312 \\
$\mathrm{C}_{9}$ & 7.053 & 15.684 & 9.198 & 13.619 & 15.270 & 7.443 \\
$\mathrm{C}_{10}$ & 4.991 & 9.362 & 7.331 & 6.914 & 9.549 & 4.783 \\
$\mathrm{C}_{11}$ & 1.860 & 3.176 & 2.443 & 2.613 & 3.020 & 2.055 \\
$\mathrm{Sum}_{\left(\mathrm{S}_{\mathrm{i}}\right)}$ & 93.328 & 159.886 & 126.754 & 127.281 & 156.526 & 98.173 \\
\hline
\end{tabular}




\subsection{Calculate the relative closeness (similarity) to the ideal solution}

A closeness coefficient $C C i$ is defined to determine the order of all possible alternatives.

Before defining $C C i$ we have to obtain $S_{i}^{*}$ and $S_{i}^{-}$as follows:

$$
\begin{aligned}
& S_{i}^{*}=\sum_{j=1}^{n} d\left(v_{i j}, v_{j}^{*}\right) \\
& S_{i}^{-}=\sum_{j=1}^{n} d\left(v_{i j}, v_{j}^{-}\right)
\end{aligned}
$$

The closeness coefficient represents the distances to the fuzzy positive ideal solution $\left(A^{*}\right)$ and fuzzy negative ideal solution ( $A^{-}$) closeness coefficient of each alternative (see Table 10) is calculated as:

$$
C C_{i}=\frac{S_{i}^{-}}{S_{i}^{*}+S_{i}^{-}}
$$

Table 10: Closeness Coefficient of each alternative

\begin{tabular}{cccc} 
& $\mathbf{A}_{\mathbf{1}}$ & $\mathbf{A}_{\mathbf{2}}$ & $\mathbf{A}_{\mathbf{3}}$ \\
\hline $\mathrm{S}^{+}$ & 93.328 & 126.754 & 156.526 \\
$\mathrm{~S}^{-}$ & 159.886 & 127.281 & 98.173 \\
$\mathrm{~S}^{-}{ }^{+}+\mathrm{S}^{-}$ & 253.215 & 254.035 & 254.699 \\
$\mathrm{CC}^{-}$ & 0.631 & 0.501 & 0.385 \\
Rank & 1 & 2 & 3 \\
\hline
\end{tabular}

\subsection{Rank the preference order}

According to the closeness coefficient, the ranking order of three alternatives is $A_{1}>A_{2}>A_{3}$. Obviously, the best selection is candidate $\mathrm{A}_{1}$.

\section{Non-Parametric Analysis}

\subsection{Kolmogorov-Smirnov and Shapiro-Wilk test}

In statistical analysis, we first have to check normality of data. If data were normal, parametric tests are used in data analyzing, else non-parametric tests should be used.so, Kolmogorov-Smirnov

\begin{tabular}{|c|c|c|c|c|c|c|}
\hline \multirow{2}{*}{ Airline_Criteria } & \multicolumn{3}{|c|}{ Kolmogorov-Smirnov } & \multicolumn{3}{|c|}{ Shapiro-Wilk } \\
\hline & Statistic & Df & Sig. & Statistic & df & Sig. \\
\hline Mahan_C1 & 0.051 & 385 & 0.017 & 0.993 & 385 & 0.055 \\
\hline Mahan_C2 & 0.095 & 385 & 0 & 0.975 & 385 & 0 \\
\hline Mahan_C3 & 0.107 & 385 & 0 & 0.98 & 385 & 0 \\
\hline Mahan_C4 & 0.128 & 385 & 0 & 0.953 & 385 & 0 \\
\hline Mahan_C5 & 0.087 & 385 & 0 & 0.986 & 385 & 0.001 \\
\hline Mahan_C6 & 0.081 & 385 & 0 & 0.988 & 385 & 0.004 \\
\hline Mahan_C7 & 0.182 & 385 & 0 & 0.934 & 385 & 0 \\
\hline Mahan_C8 & 0.12 & 385 & 0 & 0.972 & 385 & 0 \\
\hline Mahan_C9 & 0.072 & 385 & 0 & 0.982 & 385 & 0 \\
\hline Mahan_C10 & 0.071 & 385 & 0 & 0.99 & 385 & 0.007 \\
\hline Mahan_C11 & 0.077 & 385 & 0 & 0.991 & 385 & 0.02 \\
\hline IranAir_C1 & 0.039 & 385 & $.200^{*}$ & 0.991 & 385 & 0.025 \\
\hline
\end{tabular}
and Shapiro-Wilk tests are used for checking normality of data as shown in Table 11. As shown in Results, data are not normal. 


\begin{tabular}{lllllll} 
IranAir_C2 & 0.076 & 385 & 0 & 0.989 & 385 & 0.007 \\
IranAir_C3 & 0.122 & 385 & 0 & 0.979 & 385 & 0 \\
IranAir_C4 & 0.129 & 385 & 0 & 0.958 & 385 & 0 \\
IranAir_C5 & 0.079 & 385 & 0 & 0.989 & 385 & 0.006 \\
IranAir_C6 & 0.072 & 385 & 0 & 0.986 & 385 & 0.001 \\
IranAir_C7 & 0.171 & 385 & 0 & 0.947 & 385 & 0 \\
IranAir_C8 & 0.117 & 385 & 0 & 0.98 & 385 & 0 \\
IranAir_C9 & 0.074 & 385 & 0 & 0.99 & 385 & 0.008 \\
IranAir_C10 & 0.07 & 385 & 0 & 0.992 & 385 & 0.036 \\
IranAir_C11 & 0.069 & 385 & 0 & 0.993 & 385 & 0.09 \\
Aseman_C1 & 0.052 & 385 & 0.014 & 0.994 & 385 & 0.103 \\
Aseman_C2 & 0.074 & 385 & 0 & 0.99 & 385 & 0.011 \\
Aseman_C3 & 0.139 & 385 & 0 & 0.976 & 385 & 0 \\
Aseman_C4 & 0.157 & 385 & 0 & 0.961 & 385 & 0 \\
Aseman_C5 & 0.151 & 385 & 0 & 0.955 & 385 & 0 \\
Aseman_C6 & 0.102 & 385 & 0 & 0.956 & 385 & 0 \\
Aseman_C7 & 0.297 & 385 & 0 & 0.839 & 385 & 0 \\
Aseman_C8 & 0.139 & 385 & 0 & 0.976 & 385 & 0 \\
Aseman_C9 & 0.083 & 385 & 0 & 0.987 & 385 & 0.002 \\
Aseman_C10 & 0.089 & 385 & 0 & 0.967 & 385 & 0 \\
Aseman_C11 & 0.071 & 385 & 0 & 0.985 & 385 & 0.001 \\
\hline
\end{tabular}

\subsection{Friedman Test}

Due to abnormality of data, Friedman test is performed to find out rank of airlines in each criterion. The Friedman test is the non-parametric alternative to the one-way ANOVA with repeated measures. It is used to test for differences between groups when the dependent variable being measured is ordinal. Due to non-normality of data, non-parametric tests were used, So Friedman test is applied to compare average score of each airline in every criterion from the passenger view. According to results (shown in Table. 12) from passenger view, Mahan airline has performed better in all criteria and placed in the first rank and Aseman airline was placed in third rank due to weak performance in all criteria compared to other airlines.

\begin{tabular}{|c|c|c|c|c|c|}
\hline Airline/Criteria & $\mathbf{N}$ & Mean & Deviation & Mean Rank & Airline Rank \\
\hline Mahan_C1 & 385 & 5.6805195 & 0.5481737 & 2.96 & 1 \\
\hline IranAir_C1 & 385 & 4.922314 & 0.5846451 & 1.91 & 2 \\
\hline Aseman_C1 & 385 & 4.5506494 & 0.564281 & 1.13 & 3 \\
\hline Mahan_C2 & 385 & 6.0125541 & 0.4694682 & 2.92 & 1 \\
\hline IranAir_C2 & 385 & 5.5194805 & 0.5908335 & 2.04 & 2 \\
\hline Aseman_C2 & 385 & 4.604329 & 0.6041751 & 1.04 & 3 \\
\hline Mahan_C3 & 385 & 5.5688 & 0.59414 & 2.99 & 1 \\
\hline IranAir_C3 & 385 & 4.1013 & 0.58502 & 2 & 2 \\
\hline Aseman_C3 & 385 & 2.5188 & 0.56291 & 1.01 & 3 \\
\hline Mahan_C4 & 385 & 6.0805195 & 0.5053347 & 2.68 & 1 \\
\hline IranAir_C4 & 385 & 5.8969697 & 0.5713598 & 2.15 & 2 \\
\hline Aseman_C4 & 385 & 5.5593074 & 0.5652101 & 1.16 & 3 \\
\hline Mahan_C5 & 385 & 5.212 & 0.5989 & 2.96 & 1 \\
\hline IranAir_C5 & 385 & 4.408 & 0.6153 & 2.02 & 2 \\
\hline Aseman_C5 & 385 & 3.587 & 0.4676 & 1.02 & 3 \\
\hline Mahan_C6 & 385 & 5.1432282 & 0.5712889 & 2.96 & 1 \\
\hline IranAir_C6 & 385 & 4.2938776 & 0.5992459 & 1.99 & 2 \\
\hline
\end{tabular}




\begin{tabular}{lccccc}
\hline Aseman_C6 & 385 & 3.6634508 & 0.397313 & 1.05 & 3 \\
Mahan_C7 & 385 & 4.612 & 0.617 & 2.39 & 1 \\
IranAir_C7 & 385 & 4.592 & 0.6343 & 2.36 & 2 \\
Aseman_C7 & 385 & 4.066 & 0.3905 & 1.25 & 3 \\
Mahan_C8 & 385 & 5.8312 & 0.52639 & 2.95 & 1 \\
IranAir_C8 & 385 & 5.25 & 0.58575 & 2 & 2 \\
Aseman_C8 & 385 & 4.4136 & 0.59581 & 1.04 & 3 \\
Mahan_C9 & 385 & 5.606 & 0.6075 & 2.95 & 1 \\
IranAir_C9 & 385 & 4.867 & 0.6007 & 1.99 & 2 \\
Aseman_C9 & 385 & 4.166 & 0.5566 & 1.06 & 3 \\
Mahan_C10 & 385 & 5.26883 & 0.597073 & 2.99 & 1 \\
IranAir_C10 & 385 & 4.12078 & 0.553037 & 2 & 2 \\
Aseman_C10 & 385 & 3.16851 & 0.510604 & 1.01 & 3 \\
Mahan_C11 & 385 & 5.13214 & 0.594802 & 2.93 & 1 \\
IranAir_C11 & 385 & 4.74123 & 0.580902 & 2.04 & 2 \\
Aseman_C11 & 385 & 3.82987 & 0.576321 & 1.03 & 3 \\
\hline
\end{tabular}

\subsection{Analysis of Variance (ANOVA)}

In this research, for studying to see if there is any relation between age and educational level of passengers with their performance evaluation of airlines in service quality, first meaningful difference in passengers' evaluation of airlines service quality due to their individual characters, age and educational level, should be checked, so Analysis of Variance (ANOVA) is performed.

\subsection{Analysis of Variance in Age Levels}

Analysis of Variance (ANOVA) in alpha level of 0.05 between all age levels for every airline calculated. The harmonic average is used, because of different size of age groups. According to results, meaningful level of variables is higher than 0.05 . So, there is no significant difference between age level and passengers' evaluation level of airlines service quality.

\subsection{Analysis of Variance in Educational Levels}

ANOVA is also calculated between all educational levels for every airline is calculated with using the Harmonic average. According to results, meaningful level of variables is lower than 0.05 . So, there is a significant difference between passengers' educational level and their evaluation level of airlines service quality.

\subsection{Tukey's HSD Test}

While ANOVA can tell the researcher whether groups in the sample differ, it cannot tell the researcher which groups differ. Tukey's HSD test is a post-hoc test, performed after analysis of variance (ANOVA) test. If the results of ANOVA are positive in the sense that they state there is a significant difference among the groups, Tukey's HSD clarifies which groups among the sample in specific have significant differences.

HSD test is used for studying the degree of difference between educational groups. In our survey, HSD results for one criterion (Conduct) for each airline is shown in Table .13, which demonstrates that individuals with Ph.D. and Master Degrees have close opinions to each other, that in many criteria this two graduate levels placed in a shared group. Also HSD results for other criteria (see Appendix) show almost in all criteria with increasing passengers' educational level, their satisfaction and evaluation level of airlines service quality performance, decreases. As showing in results of HSD test, the numbers of 1 to 6 are used, as symbols of educational levels that are followed as: Below high school Diploma (1), High school Diploma (2), Associate (3), Bachelor (4), Master (5), PhD (6). 


\begin{tabular}{|c|c|c|c|c|c|c|c|c|c|c|c|c|c|c|c|c|}
\hline \multirow{2}{*}{ Education } & \multirow{2}{*}{$\mathbf{N}$} & \multicolumn{5}{|c|}{ Mahan_C1(Conduct) } & \multicolumn{5}{|c|}{ IranAir_C1(Conduct) } & \multicolumn{5}{|c|}{ Aseman_C1(Conduct) } \\
\hline & & 1 & 2 & 3 & 4 & 5 & 1 & 2 & 3 & 4 & 5 & 1 & 2 & 3 & 4 & 5 \\
\hline 6.0 & 15 & 4.75 & & & & & 3.98 & & & & & 3.76 & & & & \\
\hline 5.0 & 29 & 4.93 & & & & & 4.20 & & & & & 3.98 & & & & \\
\hline 4.0 & 122 & & 5.38 & & & & & 4.58 & & & & & 4.25 & & & \\
\hline 3.0 & 49 & & & 5.74 & & & & & 4.97 & & & & & 4.52 & & \\
\hline 2.0 & 134 & & & & 5.98 & & & & & 5.26 & & & & & 4.83 & \\
\hline 1.0 & 36 & & & & & 6.52 & & & & & 5.76 & & & & & 5.36 \\
\hline Sig*. & & 0.15 & 1.00 & 1.00 & 1.00 & 1.00 & 0.09 & 1.00 & 1.00 & 1.00 & 1.00 & 0.18 & 1.00 & 1.00 & 1.00 & 1.00 \\
\hline
\end{tabular}

*Subset for alpha $=0.05$

\section{Conclusions and Recommendations}

Constructing Fuzzy TOPSIS calculation in excel helped in a precise analysis. After collecting customer opinions, and using criteria weights due to expert opinions, these airlines were ranked with scores generated from Fuzzy TOPSIS analysis. According to results Mahan airline got the best score and placed in the first rank, Iran air and Aseman airline placed in second and third rank, respectively, due to customer views.

Mahan airline got the best score in service quality performance among these three airlines. This demonstrates that passengers are more satisfied with the quality of services they delivered from Mahan airline, among these three airlines. It is obvious that this airline has made a good brand in passengers' imagination .it means that Mahan airline has the potential to provide a diversity of highquality services to travelers to gain even more market share in air transportation. Iran Air and Aseman airlines should focus on their strategic planning to improve their service quality and satisfy passengers. Results of this research help airline managers to generate a standard guideline and template for developing service quality of airlines.

Using statistical techniques for analyzing customer reviews, the normality of data was checked by Kolmogorov-Smirnov and Shapiro-Wilk test. Due to the abnormality of data, Non-parametric tests were applied. Friedman test demonstrated airline ranks in every criterion separately and Mahan airline got the first rank in all criteria due to customer opinions. Variance analysis and Tukey test showed that age has no significant relation with passenger satisfaction of airlines but increasing in educational level has a negative impact on passenger's satisfaction from airlines quality. One idea about this result is, individuals with postgraduate degrees give more attention to their environment because of their critical view and having more experience of traveling with different airlines. However more research is needed to clarify this issue. Results offer a clearer perspective for airline providers, enabling them in better strategic planning, identifying airline passengers' needs and gaining remarkable market share in the airline industry. Empirical results of this research can provide useful information for airline managers to plan for their airline's service quality improvement.

\section{Appendix A. Supplementary material}

Supplementary data associated with this article can be found, in the online version, at https://jsdtl.sciview.net

\section{Funding}

The authors received no direct funding for this research.

\section{Citation information}

Haghighat, N. (2017). Proposing a framework for airline service quality evaluation using Type-2 Fuzzy TOPSIS and non-parametric analysis. Journal of Sustainable Development of Transport and Logistics, 2(2), 6-25. doi:10.14254/jsdtl.2017.2-2.1. 


\section{References}

Bolton, R. N., \& Drew. J. H. (1991). A multistage model of customers' assessments of service quality and value. Journal of consumer research, 17(4), 375-384.

Brady, M. K., \& Cronin, J. J. (2001), Some New Thoughts on Conceptualizing Perceived Service Quality: A Hierarchical Approach. The Journal of Marketing, 65(7), 34-49.

Bitner, M. J. (1990). Evaluating service encounters: the effects of physical surroundings and employee responses. Journal of Marketing, 54(2), 69-82.

Chang, Y. H., \& Yeh, C. H. (2002). A survey analysis of service quality for domestic airlines. European Journal of Operational Research, 139(1), 166-177.

Chen, J. K., \& Chen, I. S. (2010). Using a novel conjunctive MCDM approach based on DEMATEL, fuzzy ANP, and TOPSIS as an innovation support system for Taiwanese higher education. Expert Systems with Applications, 37(3), 1981-1990.

Chen, C. T. (2000). Extensions of the TOPSIS for group decision-making under fuzzy environment. Fuzzy sets and systems, 114(1), 1-9.

Cronin Jr, J. J., \& Taylor, S. A. (1992). Measuring service quality: a reexamination and extension. The journal of marketing, 55-68.

Dabholkar, P. A., Thorpe, D. I., \& Rentz, J. O. (1996). A measure of service quality for retail stores: scale development and validation. Journal of the Academy of marketing Science, 24(1), 3-16.

Cunningham, L. F., Young, C. E., \& Lee, M. (2004). Perceptions of airline service quality: pre and post 9/11. Public Works Management \& Policy, 9(1), 10-25.

Elliott, K., \& Roach, D. W. (1993). Service quality in the airline industry: are carriers getting an unbiased evaluation from consumers? Journal of Professional Service Marketing, 9(2), 71-82.

Ertuğrul, İ., \& Güneş, M. (2007). Fuzzy multi-criteria decision making method for machine selection. In Analysis and Design of Intelligent Systems using Soft Computing Techniques (pp. 638-648). Springer Berlin Heidelberg.

Ghobadian, A., Speller, S., \& Jones, M. (1994). Service quality concepts and models, International Journal of Quality \& Reliability management, 11(9), 43-66.

Gursoy, D., Chen, M. H., \& Kim, H. Y. (2005). The US airlines relative positioning based on attributes of service quality. Tourism Management, 26(1), 57-67.

Gilbert, D., \& Wong, R. K. C. (2003). Passenger expectations and airline service: a Hong Kong based study. Tourism Management, 24(5), 519-532.

Hwang, C. L., \& Yoon, K. (1981). Multiple criteria decision making. Lecture Notes in Economics and Mathematical Systems, 186.

Laming, C., \& Mason, K. (2014). Customer experience-An analysis of the concept and its performance in airline brands. Research in Transportation Business \& Management, 10, 15-25.

Liou, J. J. H., \& Tzeng, G.-H., (2007), A non-additive model for evaluating airline service quality. Journal of Air Transport Management, 13(3), 131-138.

Liou J. J. H., Hsu C.-C., Yeh W.-C., \& Lin R.-H., (2011). Using a modified grey relation method for improving airline service quality. Tourism Management, 32(6), 1381-1388.

Nadiri, H., \& Hussain, K. (2005). Perceptions of service quality in North Cyprus hotels. International Journal of Contemporary Hospitality Management, 17(6), 469-480.

Nel, D., Pitt, L. F., \& Berthon, P. R. (1997). The SERVQUAL instrument: reliability and validity in South Africa. South African Journal of Business Management, 28(3), 113-123.

Ostrowski, P. L., O'Brien, T. V., \& Gordon, G. L. (1993). Service quality and customer loyalty in the commercial airline industry. Journal of travel research, 32(2), 16-24. 
Opricovic, S., \& Tzeng, G. H. (2003). Defuzzification within a multicriteria decision model. International Journal of Uncertainty, Fuzziness and Knowledge-Based Systems, 11(05), 635-652.

Parasuraman, A., Zeithaml, V. A., \& Berry, L. L. (1985). A conceptual model of service quality and its implications for future research. The Journal of Marketing, 41-50.

Parasuraman, A., Zeithaml, V. A., \& Berry, L. L. (1988). SERVQUAL: A multiple-item scale for measuring consumer perceptions of service quality. Journal of retailing, 64(1), 12-40.

Park, J. W., Robertson, R., \& Wu, C. L. (2004). The effect of airline service quality on passengers' behavioral intentions: a Korean case study. Journal of Air Transport Management, 10(6), 435439.

Park, J. W., Robertson, R., \& Wu, C. L. (2006). The effects of individual dimensions of airline service quality: findings from Australian domestic air passengers. Journal of Hospitality and Tourism Management, 13(2), 161-176.

Pakdil, F., \& Aydin, O. (2007). Expectations and perceptions in airline service: an analysis using weighted SERVQUAL scores. Journal of Air Transport Management, 13(4), 229-237.

Sultan, F., \& Simpson Jr, M. C. (2000). International service variants: airline passenger expectations and perceptions of service quality. Journal of services marketing, 14(3), 188-216.

Tsaur, S. H., Chang, T. Y., \& Yen, C. H. (2002). The evaluation of airline service quality by fuzzy MCDM. Tourism management, 23(2), 107-115.

Truitt, L. J., \& Haynes, R. (1994). Evaluating service quality and productivity in the regional airline industry. Transportation Journal, 33(2), 21-32.

Wu, J. H. C., Lin, Y. C., \& Hsu, F. S. (2011). An empirical analysis of synthesizing the effects of service quality, perceived value, corporate image and customer satisfaction on behavioral intentions in the transport industry: a case of Taiwan high-speed rail. Innovative Marketing, 7(3), 83-100.

Wu, H. C., \& Cheng, C. C. (2013). A hierarchical model of service quality in the airline industry. Journal of Hospitality and Tourism Management, 20, 13-22.

Zadeh, L. A. (1975). The concept of a linguistic variable and its application to approximate reasoningII. Information sciences, 8(4), 301-357. 


\section{Appendix}

\section{Table 14: HSD test for (C2) Expertise criterion of the three airlines}

\begin{tabular}{|c|c|c|c|c|c|c|c|c|c|c|c|c|c|c|c|c|}
\hline \multirow{2}{*}{ Education } & \multicolumn{7}{|c|}{ Mahan_C2(Expertise) } & \multicolumn{5}{|c|}{ IranAir_C2(Expertise) } & \multicolumn{4}{|c|}{ Aseman_C2(Expertise) } \\
\hline & N & 1 & 2 & 3 & 4 & 5 & 6 & 1 & 2 & 3 & 4 & 5 & 1 & 2 & 3 & 4 \\
\hline 6.0 & 15 & 5.21 & & & & & & 4.55 & & & & & 3.82 & & & \\
\hline 5.0 & 29 & & 5.42 & & & & & 4.8 & & & & & 3.84 & & & \\
\hline 4.0 & 122 & & & 5.75 & & & & & 5.2 & & & & & 4.25 & & \\
\hline 3.0 & 49 & & & & 6.01 & & & & & 5.54 & & & & & 4.66 & \\
\hline 2.0 & 134 & & & & & 6.3 & & & & & 5.86 & & & & 4.94 & \\
\hline 1.0 & 36 & & & & & & 6.65 & & & & & 6.3 & & & & 5.37 \\
\hline Sig. & & 0.100 & 1.00 & 1.00 & 1.00 & 1.00 & 1.00 & 0.065 & 1.00 & 1.00 & 1.00 & 1.00 & 1.00 & 1.00 & 0.51 & 1.00 \\
\hline
\end{tabular}

\section{Table 15: HSD test for (C3) Problem-Solving criterion of the three airlines}

\begin{tabular}{|c|c|c|c|c|c|c|c|c|c|c|c|c|c|c|c|}
\hline \multirow{2}{*}{ Education } & \multirow{2}{*}{$\mathbf{N}$} & \multicolumn{5}{|c|}{ Mahan_C3(Problem-Solving) } & \multicolumn{5}{|c|}{ IranAir_C3(Problem-Solving) } & \multicolumn{4}{|c|}{ Aseman_C3(Problem-Solving) } \\
\hline & & 1 & 2 & 3 & 4 & 5 & 1 & 2 & 3 & 4 & 5 & 1 & 2 & 3 & 4 \\
\hline 6.0 & 15 & 4.63 & & & & & 3.11 & & & & & 1.78 & & & \\
\hline 5.0 & 29 & 4.83 & & & & & 3.25 & & & & & 1.79 & & & \\
\hline 4.0 & 122 & & 5.27 & & & & & 3.8 & & & & & 2.23 & & \\
\hline 3.0 & 49 & & & 5.6 & & & & & 4.17 & & & & & 2.57 & \\
\hline 2.0 & 134 & & & & 5.88 & & & & & 4.41 & & & & 2.81 & \\
\hline 1.0 & 36 & & & & & 6.34 & & & & & 4.94 & & & & 3.18 \\
\hline Sig. & & 0.311 & 1.00 & 1.00 & 1.00 & 1.00 & 0.523 & 1.00 & 1.00 & 1.00 & 1.00 & 1.00 & 1.00 & 0.94 & 1.00 \\
\hline
\end{tabular}

\section{Table 16: HSD test for (C4) Cleanliness criterion of the three airlines}

\begin{tabular}{|c|c|c|c|c|c|c|c|c|c|c|c|c|c|c|c|}
\hline \multirow{2}{*}{ Education } & \multirow{2}{*}{$\mathbf{N}$} & \multicolumn{4}{|c|}{ Mahan_C4(Cleanliness) } & \multicolumn{5}{|c|}{ IranAir_C4(Cleanliness) } & \multicolumn{5}{|c|}{ Aseman_C4(Cleanliness) } \\
\hline & & 1 & 2 & 3 & 4 & 1 & 2 & 3 & 4 & 5 & 1 & 2 & 3 & 4 & 5 \\
\hline 6.0 & 15 & 5.35 & & & & 5.02 & & & & & 4.57 & & & & \\
\hline 5.0 & 29 & 5.42 & & & & 5.19 & & & & & & 4.82 & & & \\
\hline 4.0 & 122 & & 5.82 & & & & 5.55 & & & & & & 5.24 & & \\
\hline 3.0 & 49 & & 5.97 & 6.4 & & & & 4.92 & & & & & & 5.7 & \\
\hline 2.0 & 134 & & & & 6.73 & & & & 6.23 & & & & & 5.8 & \\
\hline 1.0 & 36 & & & & & & & & & 6.69 & & & & & 6.35 \\
\hline Sig. & & 0.943 & 0.384 & 1.00 & 1.00 & 0.288 & 1.00 & 1.00 & 1.00 & 1.00 & 1.00 & 1.00 & 1.00 & 0.509 & 1.00 \\
\hline
\end{tabular}

\section{Table 17: HSD test for (C5) Comfort criterion of the three airlines}

\begin{tabular}{|c|c|c|c|c|c|c|c|c|c|c|c|c|c|c|c|c|c|}
\hline \multirow{2}{*}{ Education } & \multirow{2}{*}{$\mathbf{N}$} & \multicolumn{6}{|c|}{ Mahan_C5(Comfort) } & \multicolumn{5}{|c|}{ IranAir_C5(Comfort) } & \multicolumn{5}{|c|}{ Aseman_C5(Comfort) } \\
\hline & & 1 & 2 & 3 & 4 & 5 & 6 & 1 & 2 & 3 & 4 & 5 & 1 & 2 & 3 & 4 & 5 \\
\hline 6.0 & 15 & 4.17 & & & & & & 3.37 & & & & & 2.99 & & & & \\
\hline 5.0 & 29 & & 4.50 & & & & & 3.95 & & & & & 2.99 & & & & \\
\hline 4.0 & 122 & & & 4.86 & & & & & 4.1 & & & & & 3.32 & & & \\
\hline 3.0 & 49 & & & & 5.3 & & & & & 4.36 & & & & & 3.6 & & \\
\hline 2.0 & 134 & & & & & 5.54 & & & & & 4.76 & & & & & 3.8 & \\
\hline 1.0 & 36 & & & & & & 6.07 & & & & & 5.28 & & & & & 4.37 \\
\hline Sig. & & 1.00 & 1.00 & 1.00 & 1.00 & 1.00 & 1.00 & $0.134 \mid$ & 1.00 & 1.00 & 1.00 & 1.00 & 1.00 & 1.00 & 1.00 & 1.00 & 1.00 \\
\hline
\end{tabular}


Table 18: HSD test for (C6) Tangibles criterion of the three airlines

\begin{tabular}{|c|c|c|c|c|c|c|c|c|c|c|c|c|c|c|c|c|}
\hline \multirow{2}{*}{ Education } & & \multicolumn{5}{|c|}{ Mahan_C6(Tangibles) } & \multicolumn{5}{|c|}{ IranAir_C6(Tangibles) } & \multicolumn{5}{|c|}{ Aseman_C6(Tangibles) } \\
\hline & & 1 & 2 & 3 & 4 & 5 & 1 & 2 & 3 & 4 & 5 & 1 & 2 & 3 & 4 & 5 \\
\hline 6.0 & 15 & 4.42 & & & & & 3.31 & & & & & 3.13 & & & & \\
\hline 5.0 & 29 & 4.43 & & & & & 3.54 & & & & & 3.26 & 3.26 & & & \\
\hline 4.0 & 122 & & 4.82 & & & & & 3.95 & & & & & 3.4 & & & \\
\hline 3.0 & 49 & & & 5.14 & & & & & 4.34 & & & & & 3.66 & & \\
\hline 2.0 & 134 & & & & 5.45 & & & & & 4.64 & & & & & 3.87 & \\
\hline 1.0 & 36 & & & & & 5.94 & & & & & 5.1 & & & & & 4.28 \\
\hline Sig. & & 1.00 & 1.00 & 1.00 & 1.00 & 1.00 & 0.106 & 1.00 & 1.00 & 1.00 & 1.00 & 0.210 & 0.181 & 1.00 & 1.00 & 1.00 \\
\hline
\end{tabular}

\section{Table 19: HSD test for (C7) Safety\&Security criterion of the three airlines}

\begin{tabular}{|c|c|c|c|c|c|c|c|c|c|c|c|c|c|c|c|c|}
\hline \multirow{2}{*}{ Education } & \multirow{2}{*}{$\mathbf{N}$} & \multicolumn{5}{|c|}{ Mahan_C7(Safety\&Security) } & \multicolumn{5}{|c|}{ IranAir_C7(Safety\&Security) } & \multicolumn{5}{|c|}{ Aseman_C7(Safety\&Security) } \\
\hline & & 1 & 2 & 3 & 4 & 5 & 1 & 2 & 3 & 4 & 5 & 1 & 2 & 3 & 4 & 5 \\
\hline 6.0 & 15 & 3.7 & & & & & 3.66 & & & & & 3.6 & & & & \\
\hline 5.0 & 29 & 3.77 & & & & & 3.86 & & & & & 3.73 & 3.73 & & & \\
\hline 4.0 & 122 & & 4.29 & & & & & 4.24 & & & & & 3.9 & 3.89 & & \\
\hline 3.0 & 49 & & & 4.59 & & & & & 4.58 & & & & & 4 & & \\
\hline 2.0 & 134 & & & & 5 & & & & & 4.94 & & & & & 4.24 & \\
\hline 1.0 & 36 & & & & & 5.3 & & & & & 5.45 & & & & & 4.58 \\
\hline Sig. & & 0.97 & 1.00 & 1.00 & 1.00 & 1.00 & 0.366 & 1.00 & 1.00 & 1.00 & 1.00 & 0.420 & 0.192 & 0.543 & 1.00 & 1.00 \\
\hline
\end{tabular}

\section{Table 20: HSD test for (C8) Valence criterion of the three airlines}

\begin{tabular}{|c|c|c|c|c|c|c|c|c|c|c|c|c|c|c|c|c|c|c|}
\hline \multirow{2}{*}{ Education } & \multirow{2}{*}{$\mathbf{N}$} & \multicolumn{6}{|c|}{ Mahan_C8(Valence) } & \multicolumn{6}{|c|}{ IranAir_C8(Valence) } & \multicolumn{5}{|c|}{ Aseman_C8(Valence) } \\
\hline & & 1 & 2 & 3 & 4 & 5 & 6 & 1 & 2 & 3 & 4 & 5 & 6 & 1 & 2 & 3 & 4 & 5 \\
\hline 6.0 & 15 & 4.88 & & & & & & 4.21 & & & & & & 3.51 & & & & \\
\hline 5.0 & 29 & & 5.13 & & & & & & 4.47 & & & & & 3.58 & & & & \\
\hline 4.0 & 122 & & & 5.58 & & & & & & 4.95 & & & & & 4.1 & & & \\
\hline 3.0 & 49 & & & & 5.86 & & & & & & 5.24 & & & & & 4.5 & & \\
\hline 2.0 & 134 & & & & & 6.1 & & & & & & 5.58 & & & & 4.7 & & \\
\hline 1.0 & 36 & & & & & & 6.61 & & & & & & 6.1 & & & & 5.25 & \\
\hline Sig. & & 1.00 & 1.00 & 1.00 & 1.00 & 1.00 & 1.00 & 1.00 & 1.00 & 1.00 & 1.00 & 1.00 & 1.00 & 0.971 & 1.00 & 0.142 & 1.00 & \\
\hline
\end{tabular}

\section{Table 21: HSD test for (C9) Waiting Time criterion of the three airlines}

\begin{tabular}{|c|c|c|c|c|c|c|c|c|c|c|c|c|c|c|c|c|c|c|}
\hline \multirow{2}{*}{ Education } & \multirow{2}{*}{$\mathbf{N}$} & \multicolumn{6}{|c|}{ Mahan_C8(Valence) } & \multicolumn{6}{|c|}{ IranAir_C8(Valence) } & \multicolumn{5}{|c|}{ Aseman_c8(Valence) } \\
\hline & & 1 & 2 & 3 & 4 & 5 & 6 & 1 & 2 & 3 & 4 & 5 & 6 & 1 & 2 & 3 & 4 & 5 \\
\hline 6.0 & 15 & 4.88 & & & & & & 4.21 & & & & & & 3.51 & & & & \\
\hline 5.0 & 29 & & 5.13 & & & & & & 4.47 & & & & & 3.58 & & & & \\
\hline 4.0 & 122 & & & 5.58 & & & & & & 4.95 & & & & & 4.1 & & & \\
\hline 3.0 & 49 & & & & 5.86 & & & & & & 5.24 & & & & & 4.5 & & \\
\hline 2.0 & 134 & & & & & 6.1 & & & & & & 5.58 & & & & 4.7 & & \\
\hline 1.0 & 36 & & & & & & 6.61 & & & & & & 6.1 & & & & 5.25 & \\
\hline Sig. & & 1.00 & 1.00 & 1.00 & 1.00 & 1.00 & 1.00 & 1.00 & 1.00 & 1.00 & 1.00 & 1.00 & 1.00 & 0.971 & 1.00 & 0.142 & 1.00 & \\
\hline
\end{tabular}


Table 22: HSD test for (C10) Information criterion of the three airlines

\begin{tabular}{|c|c|c|c|c|c|c|c|c|c|c|c|c|c|c|c|c|}
\hline \multirow{2}{*}{ Education } & \multirow{2}{*}{$\mathbf{N}$} & \multicolumn{5}{|c|}{ Mahan_C10(Information) } & \multicolumn{5}{|c|}{ IranAir_C10(Information) } & \multicolumn{5}{|c|}{ Aseman_C10(Information) } \\
\hline & & 1 & 2 & 3 & 4 & 5 & 1 & 2 & 3 & 4 & 5 & 1 & 2 & 3 & 4 & 5 \\
\hline 6.0 & 15 & 4.42 & & & & & 3.37 & & & & & 2.46 & & & & \\
\hline 5.0 & 29 & 4.51 & & & & & 3.38 & & & & & 2.56 & & & & \\
\hline 4.0 & 122 & & 4.93 & & & & & 3.8 & & & & & 2.84 & & & \\
\hline 3.0 & 49 & & & 5.3 & & & & & 4.13 & & & & & 3.17 & & \\
\hline 2.0 & 134 & & & & 5.57 & & & & & 4.43 & & & & & 3.45 & \\
\hline 1.0 & 36 & & & & & 6.2 & & & & & 4.95 & & & & & 3.96 \\
\hline Sig. & & 0.914 & 1.00 & 1.00 & 1.00 & 1.00 & 1.00 & 1.00 & 1.00 & 1.00 & 1.00 & 0.747 & 1.00 & 1.00 & 1.00 & 1.00 \\
\hline
\end{tabular}

\section{Table 23. HSD test for (C11) Convenience criterion of the three airlines}

\begin{tabular}{|c|c|c|c|c|c|c|c|c|c|c|c|c|c|c|c|c|c|}
\hline \multirow{2}{*}{ Education } & \multirow{2}{*}{$\mathbf{N}$} & \multicolumn{6}{|c|}{ Mahan_C11(Convenience) } & \multicolumn{5}{|c|}{ IranAir_C11(Convenience) } & \multicolumn{5}{|c|}{ Aseman_C11(Convenience) } \\
\hline & & 1 & 2 & 3 & 4 & 5 & 6 & 1 & 2 & 3 & 4 & 5 & 1 & 2 & 3 & 4 & 5 \\
\hline 6.0 & 15 & 4.03 & & & & & & 3.81 & & & & & 3.01 & & & & \\
\hline 5.0 & 29 & & 4.41 & & & & & 3.95 & & & & & 3.09 & & & & \\
\hline 4.0 & 122 & & & 4.79 & & & & & 4.42 & & & & & 3.52 & & & \\
\hline 3.0 & 49 & & & & 5.15 & & & & & 4.81 & & & & & 3.83 & & \\
\hline 2.0 & 134 & & & & & 5.49 & & & & & 5.06 & & & & & 4.12 & \\
\hline 1.0 & 36 & & & & & & 5.95 & & & & & 5.58 & & & & & 4.7 \\
\hline Sig. & & 1.00 & 1.00 & 1.00 & 1.00 & 1.00 & 1.00 & 0.499 & 1.00 & 1.00 & 1.00 & 1.00 & 0.956 & 1.00 & 1.00 & 1.00 & 1.00 \\
\hline
\end{tabular}

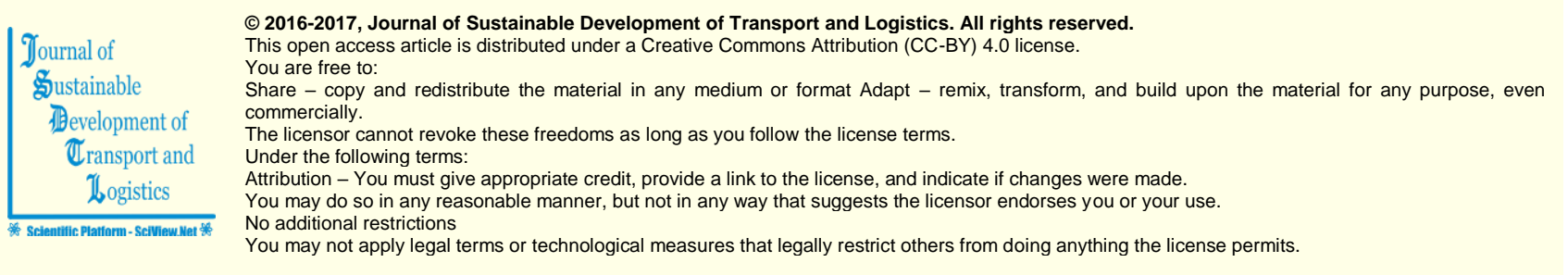

Journal of Sustainable Development of Transport and Logistics (ISSN: 2520-2979) is published by Scientific Publishing House "CSR", Poland, EU and Scientific Publishing House "SciView", Poland, EU

Publishing with JSDTL ensures:

- Immediate, universal access to your article on publication

- High visibility and discoverability via the JSDTL website

- Rapid publication

- Guaranteed legacy preservation of your article

- Discounts and waivers for authors in developing regions

Submit your manuscript to a JSDTL at http://jsdtl.sciview.net/ or submit.jsdtI@sciview.net 